\title{
Statistical Bias and Endorsement of Conspiracy Theories
}

\author{
Neil Dagnall*, Andrew Denovan, Kenneth Drinkwater, Andrew Parker and \\ Peter Clough
}

Department of Psychology, Manchester Metropolitan University, Manchester, UK

Summary: Previous research proposes that endorsement of anomalous beliefs is associated with proneness to conjunction error. This supposition ignores important differences between belief types. Correspondingly, the present study examined the degree to which components of statistical bias predicted conspiratorial ideation and belief in the paranormal. Confirmatory factor analysis and structural equation modelling revealed that conjunction error was associated with conspiratorial ideation, whilst perception of randomness most strongly predicted belief in the paranormal. These findings opposed the notion that anomalous beliefs, by virtue of possession of common characteristics, relate similarly to conjunction error. With regard to conspiracy, conjunction-framing manipulations produced only minor variations in relationship strength. This supported the notion that conspiratorial ideation was associated with a domaingeneral susceptibility to conjunction error. Framing, however, did influence the relationship between belief in the paranormal and conjunction; whilst, paranormal conjunctions were generally easier to solve, performance declined as level of paranormal belief increased.

Keywords: belief in the paranormal, conspiracy, framing effects, statistical bias

The final publication of this article is available at Wiley via:

\section{http://dx.doi.org/10.1002/acp.3331}

*Correspondence to: Neil Dagnall, Department of Psychology, MMU, Birley, Bonsall Street, Manchester M15 6GX, UK.

E-mail: n.dagnall@mmu.ac.uk 
Several studies report a link between endorsement of unconventional beliefs and proneness to statistical bias. Principally, belief in the paranormal (Dagnall, Drinkwater, Denovan, Parker, \& Rowley, 2016; Dagnall, Drinkwater, Parker, \& Rowley, 2014; Dagnall, Parker, \& Munley, 2007; Rogers, Fisk, \& Wiltshire, 2011; Rogers, Fisk, \& Lowrie, 2016), and latterly endorsement of conspiracy theories (Brotherton \& French, 2014). However, few studies consider the degree to which belief types are differentially associated with components of statistical bias (i.e., perception of randomness and conjunction error), and whether relationship strength varies as a function of framing. This paper examined these important questions (primarily) in the context of conspiratorial beliefs.

\section{Conspiracism}

Current academic interest in the psychological correlates of conspiratorial ideation is high. Despite this, there remains no single, commonly recognised definition of conspiracy (Sunstein \& Vermeule, 2009). Generally, conceptual delineations share the assumption that conspiracy theories comprise multiple actors, who collude in order to orchestrate malevolent plots (Barron, Morgan, Towell, Altemeyer, \& Swami, 2014). More recently, theorists also conceptualise conspiracism as a coherent and distinct generalised political attitude or mentality (Imhoff \& Bruder, 2014).

Endorsement of conspiracy theories occurs (usually) when individuals perceive official, predominant narratives as deficient, or there is no agreed/consensual explanation for socially/politically important events. Drawing upon these thematic elements, Brotherton and French (2014) describe a conspiracy theory as, "an unverified and relatively implausible allegation of conspiracy, claiming that significant events are the result of a secret plot carried out by a preternaturally sinister and powerful group of people" (p. 138). 


\section{Proneness to statistical bias and conspiracies}

Brotherton and French (2014) conducted two studies to determine whether endorsement of anomalous beliefs (conspiratorial ideation and belief in the paranormal) was associated with propensity to conjunction error. Conjunction fallacy occurs when individuals rate the likelihood of event co-occurrence higher than independent constituent elements (Tversky \& Kahneman, 1982). In Study 1, participants completed an extended version of the Scenario Judgements Questionnaire (SJQ; Rogers, Davis, \& Fisk, 2009), a measure of real-world conspiracy theory endorsement (Douglas \& Sutton, 2011), and a general scale assessing belief in the paranormal (the Australian Sheep Goat Scale, ASGS; Thalbourne \& Delin, 1993).

The SJQ assesses susceptibility to conjunction fallacy via vignettes. Each vignette described a situation, followed by three statements related to potential outcomes: two component statements (A \& B), plus the statements combined (conjunction) (AB). For example, 'A group of students go to a popular pub after a lecture. The pub is only a five minute walk from the university and it is also close to town. There is a beer garden outside the pub.' Participants rate the probability that (i) it is a warm summer's day; (ii) there are people sitting in the beer garden; and (iii) it is a warm summer's day, and there are people sitting in the beer garden'. Furthermore, conjunctions appeared within three contexts (neutral, conspiratorial and implied paranormal event). Neutral referred to common everyday situations (e.g., café and horse race). Conspiratorial resembled allegations found in popular conspiracy theories, such as industrial and political concealment of reputation damaging information. Paranormal scenarios indicated the possibility of an ostensibly paranormal event (e.g., consulting a medium about a possible inheritance).

Stronger endorsement of conspiracies was moderately associated with greater numbers of conjunction errors. There was a trend for participants with higher belief in the paranormal to produce more mistakes (Rogers et al., 2009, 2011). However, paranormal belief-related 
effects were weak and bordered on the cusp of statistical significance. Thus, study 1 produced a qualified replication of Rogers' finding (Rogers et al., 2009, 2011); only median split analysis (not correlation) supported the notion that paranormal believers (vs. non-believers) were more prone to conjunction error. Additionally, contextual factors influenced susceptibility to conjunction bias. Participants made fewer errors on paranormal-based scenarios (vs. neutral or conspiracy-themed items).

Noting limitations arising from the use of particular conspiracies, principally high endorsement of an item referring to the death of Princess Diana, Brotherton and French (2014) undertook a second study. This acted as a replication and a test of reliability. Study 2 assessed conspiratorial ideation via the 'The Generic Conspiracist Beliefs Scale' (GBC; Brotherton, French \& Pickering, 2013). The GBC is a psychometrically validated measure of universal belief in conspiracies.

Noting the weak association between belief in the paranormal and conjunction error, study 2 omitted this factor. Findings replicated the effects reported in Study 1. Stronger conspiracist ideation was associated with higher numbers of conjunction errors. In addition, framing had no effect on conjunction error rate. Correspondingly, Brotherton and French (2014) concluded that belief in conspiracies was associated with domain-general susceptibility to conjunction fallacy. However, recent work by Dieguez, Wagner-Egger and Gauvrit (2015), found no relationship between the ability to detect randomness within binary strings and conspiracist ideation. This may be attributable to the fact that Dieguez et al (2015) examined perception of randomness via approximate-complexity rather than probabilistic reasoning. 


\section{Proneness to statistical bias and belief in the paranormal}

Previous work has focused on relationships between statistical bias and belief in the paranormal. It is important to consider this body of research because it informed the approach used by Brotherton \& French (2014).

There is an established research tradition explicating links between belief in the paranormal and reasoning bias (cf. Blackmore \& Troscianko, 1985). Building on seminal work, Dagnall et al (2007) examined whether belief in the paranormal was associated with specific failures in probabilistic reasoning. Participants completed the Revised Paranormal Belief Scale (R-PBS) (Tobacyk, 2004) alongside a series of problem-solving tasks: perception of randomness (likelihood of sequence occurrence), base rate (prospect of a stated outcome in relation to prior odds), conjunction fallacy (determining whether co-occurring events were more likely than constituent elements) and derivation of expected value (evaluating odds in order to maximise winnings). Analysis indicated that a deficit related to misperception of randomness (wrongly inferred causality) best predicted belief in the paranormal.

This outcome was consistent with Brugger \& Taylor (2003), who reported that paranormal believers were more likely to view coincidences (co-occurring random events) as meaningful. The Dagnall et al. (2007) paper was important because it recognised a link between faulty ascription of causality (misperception of chance) \& belief in the paranormal. Collectively, these studies indicated that misperception of chance (inaccurate perception of randomness, illusory causation) was an important prognosticator of paranormal belief.

Rogers et al. (2009) contended that methodological limitations within the Dagnall et al. (2007) study resulted in an underestimation of the importance of conjunction error. Accordingly, Rogers compared believers vs. non-believer performance on conjunctions (paranormal vs. non-paranormal). Believers made more errors, although response format (probability vs. frequency estimations) had no effect. Additionally, participants produced fewer 
conjunction errors for paranormal events. Building on these findings, Rogers et al. (2011) performed a further study. This time, each problem type (paranormal vs. non-paranormal) comprised two events (virtually co-occurring vs. temporally disjointed). Believers again, regardless of problem \& event manipulation, produced more conjunction errors.

Due to the weak and inconsistent nature of effects observed within the Rogers et al studies, further research considering the relative importance of conjunction (vs. perception of randomness) was undertaken. Specifically, Dagnall et al. (2014) refuted Rogers et al. (2009, 2011) contentious claim that the failure to observe a conjunction effect in their 2007 study was attributable to methodological weaknesses. Dagnall et al. (2014) extended the original work by including a measure of proneness to reality testing (RT); the inclination to test critically the logical plausibility of beliefs (Irwin, 2004). In this study, perception of randomness best predicted level of paranormal belief \& proneness to RT deficits. Contrastingly, conjunction only significantly correlated (weakly) with the traditional paranormal belief (TPB) dimension of the RPBS. Finally, a framing effect occurred, paranormal conjunction (vs. standard) problems correlated more strongly (moderately) with level of paranormal belief $\&$ proneness to RT deficits (weakly).

Noting the weak, inconsistent nature of the conjunction effect, Dagnall et al. (2016) attempted to reconcile \& rationalise the influence of statistical bias. To achieve this, they tested the notion that that conjunction represented a particular instance of misperception of randomness (Arnott, 1998, 2006). As predicted, perception of randomness was more strongly associated with belief in the paranormal. Again, conjunction correlated weakly with only TPB. Furthermore, presenting scenarios within a paranormal context weakened their predictive power. Overall, findings were attributable to the fact that conjunction tasks indirectly indexed misperception of randomness (Dagnall et al., 2016, Rogers, 2014). 


\section{The present study}

The notion that belief in the paranormal and endorsement of conspiracies are similarly related to statistical basis derives from the inference that anomalous beliefs are collectively defined by possession of shared characteristics, particularly defiance of reality. Whilst this view appears conceptually coherent and logical, it is not consistent with observed findings. For instance, consideration of correlation coefficient sizes within the Brotherton and French (2014) study revealed important belief-related variations; conspiracism correlated moderately with conjunction, whilst the relationship between belief in the paranormal and conjunction error was weak. The latter outcome was congruent with previous work reporting small, inconsistent associations between paranormal belief and susceptibility to conjunction error (see Dagnall et al., 2014, 2016).

Variance in coefficient strength is not surprising because conspiracism and belief in the paranormal represent distinct, but intersecting constructs. This is evidenced by the intermeasure correlations, which are typically within the $.30-.50$ range (low to moderate) (see Darwin, Neave, \& Holmes, 2011; Drinkwater, Dagnall, \& Parker, 2012; Lobato, Mendoza, Sims, \& Chin, 2014; Swami et al., 2011). These indicate that the constructs share only approximately 9\%-25\% variance (Dagnall et al., 2016).

Usefully, Brotherton and French (2014) suggest criteria for operationalising dissimilarities between anomalous belief types. These applied to the current study provided a sound basis for subsequent predictions. Particularly, the supposition that conspiracism and belief in the paranormal interact differently with components of statistical bias (conjunction and perception of randomness). In this context, careful consideration of key features of conspiracism and belief in the paranormal is important.

Validation of paranormal phenomena requires acceptance of the possibility that concepts and powers, which contradict prevailing scientific principles and challenge/dispute 
fundamental views of the materialist world exist (see Broad, 1949; basic limiting principles). Hence, belief in several paranormal aspects (psi, ghosts, astrology, etc.) draws heavily on causal inference. Particularly, believers deduce meaningful interactions between potential causes/effects and explain them via attributional processes, which reference paranormal explanations. In such instances, misperception of chance is likely to influence interpretation. This elucidation is commensurate with the robustly reported significant association between misperception of chance (randomness) and belief in the paranormal. The weaker relationship between belief in the paranormal and conjunction is explicable in terms of Arnott's taxonomy of decision biases $(1998,2006)$. This defines appreciation of chance and conjunction error as connected, but discrete forms of statistical bias. Consequently, in the context of paranormal belief, conjunction represents a particular instance of perception of randomness (Dagnall et al., 2014, 2016; Rogers, 2014).

Contrastingly, conspiracies typically draw on real world events and happenings. The unconventional nature of conspiratorial thinking stems generally from inferences and suppositions about actor actions, intentions and behaviour, rather than allusion to scientifically unknown powers, forces and entities. That stated, the authors acknowledge that some conspiracy theories contain paranormal elements. In the case of conspiracies, reason is confounded when perceived factual inadequacies form the basis for acceptance of alternative explanations. Premises combine in such a way that likelihood of conspiracy veracity is dependent upon deficiencies within the official account. From this perspective, conspiratorial ideation superficially mirrors the archetypal structure of conjunction errors; conspiracy legitimacy draws on the falseness of other factors, and/or evidences malevolent manipulation of parties/agencies (i.e., powerful groups/ individuals). Dagnall et al. $(2014,2016)$ use the example of the 1947 Roswell incident, where conspiracy endorsers often cite deficiencies 
within formal accounts as direct evidence for the existence of extra-terrestrial life (Nickell, 2009; Thomas, 1995).

The notion that propensity to conjunction varies as a function of belief is supported by recent work. For instance, Dagnall et al. $(2014,2016)$ reported that conjunction error correlated only with TPB; the relationship with new age philosophy was not significant. Additionally, Rogers et al. (2016) examined paranormal believers' susceptibility to conjunction fallacy for confirming versus disconfirming conjunctive events. Using ASGS factors, Rogers et al. (2016) reported that belief in extrasensory perception \& psychokinesis were associated with heightened susceptibility to generic conjunction fallacy, whilst life after death approached significance. They observed also that more errors occurred for confirmatory (vs. disconfirmatory) conjunctions regardless of event type (paranormal versus non-paranormal). This finding was consistent with Crupi \& Tentori's Confirmation Theoretical Framework (Tentori, Crupi, \& Russo, 2013), which proposed that previously acquired evidence influences hypothesis confirmation. In the case of conjunction, error is most likely to arise when evidence inherent within the first constituent inductively confirms the second. When the preceding data disconfirms the subsequent statement (fails to support it), conjunction is less probable. These conditions appear apposite to conspiratorial ideation rather than belief in the paranormal.

Within the present study, the authors predicted that statistical bias components (perception of randomness and conjunction fallacy) would correlate moderately and relate differentially to conspiratorial ideation and belief in the paranormal. Explicitly, conjunction would associate more strongly with endorsement of conspiracy theories, and perception of randomness with belief in the paranormal. Finally, to ascertain whether framing effected susceptibility to conjunction error a comparison of relationships between conjunction manipulations and belief types was undertaken. Conjunction contexts reflected previous research and included standard, everyday, conspiracy and paranormal situations. Based on 
Brotherton and French's (2014) conclusion that belief in conspiracies was associated with domain-general susceptibility to conjunction fallacy the authors predicted similar moderate relationships across conjunction manipulations. Noting, that previous studies often report that placing conjunctions in a paranormal context increases solution rate and that this advantage lessens as a function of belief in the paranormal, a stronger correlation was predicted between paranormal beliefs and paranormal conjunctions.

\section{METHOD}

\section{Participants}

A sample of 246 participants (62 male, $25 \%$ and 184 female, $75 \%$ ) took part in the study. Mean age $25.21, S D=10.25$, range $18-67$ years. Males, $M=27.18, S D=11.51$, range $18-52$ years, and females, $M=24.56, S D=9.72$, range 18-67 years. Participant recruitment was via emails to university staff/students and local stakeholders (businesses, leisure and vocational/sports classes). The sample comprised $75 \%$ undergraduates, $12 \%$ postgraduates and $13 \%$ nonstudents. In terms of highest qualifications: $58 \%$ pre-degree, $28 \%$ graduates, and $14 \%$ postgraduates. If potential participants were younger than 18 years of age, or declared they had previously studied heuristic bias, participation discontinued. These were the only exclusion criteria.

\section{Materials}

Probabilistic reasoning tasks

Problem type manipulation assessed susceptibility to statistical bias (i.e., perception of randomness and conjunction fallacy). Previous related research informed problem task selection (see Dagnall et al., 2007, 2014 \& 2016). 


\section{Perception of randomness}

Items assessed participant's ability to judge the likelihood of strings/sequences (e.g., 'imagine a coin was tossed six times. Which pattern of results do you think is most likely? HHHHHH, (b) HHHTTT, (c) HTHHTT, (d) all equally likely’.

\section{Conjunction fallacy}

Conjunction problems required participants to indicate the most probable outcome from a series of presented alternatives. Conjunctions appeared within four contexts (standard, every day, conspiratorial and paranormal). Within each conjunction type, underlying problem structure was the same, only surface characteristics varied. Thus, event intersection never exceeded the likelihood of single constituent events (cf. Tversky \& Kahneman, 1982, 1983). Instructions directed participants to select the most likely possibility from a series of alternatives. These comprised single component events (A and B) and a conjunction (both events co-occurring, $\mathrm{AB}$ ).

\section{Standard}

'Standard' problems originated from the classic work of Tversky \& Kahneman (1982, 1983). Items related to a range of topics (e.g., heart attack, Linda problem, cause of war, and outcome of sporting events). For example, 'two football teams (Team A and Team B) are playing in a local derby. What is the most likely outcome?: (a) Team A scores first, (b) Team A scores first and wins, (c) Team A scores first and loses, (d) Team A scores first and the game is drawn'. These problems have featured in several recent papers (see Dagnall et al., 2007, 2014 \& 2016). Everyday

These items derived from Brotherton and French (2014), presented conjunctions in commonly encountered, daily setting (i.e. visit to a public house, traffic diversion, shopping trip, cycling journey and meal at a restaurant). For instance, 'A group of students go to a popular pub after a lecture. The pub is only a five-minute walk from the university and it is close to town. There 
is a beer garden outside the pub. What is the most likely outcome?: (a) it is a warm summer's day, (b) there are people sitting in the beer garden, and (c) it is a warm summer's day, and there are people sitting in the beer garden'.

\section{Conspiracy}

Items embodied claims typically found within conspiracy theories (loss of vital data, fuel efficiency invention, scientific breakthrough, political scandal and inadequate social care). Consistent with Brotherton and French (2014) themes implied that powerful people and institutions (pharmaceutical companies, politicians and industries) were manipulating events, managing information in order to foster financial, social and political gain. Illustratively, 'Patrick works for a pharmaceutical company testing the efficacy and side-effects of some of the drugs they manufacture. He discovers that one of their widely available over-the-counter drugs is associated with an increased risk of heart disease. What is the most likely outcome?:

(a) Patrick's data were lost after an IT failure affecting his computer; (b) Patrick is taken off the project; and (c) Patrick's data were lost after an IT failure affecting his computer, and Patrick is taken off the project'.

\section{Paranormal}

Paranormal scenarios placed conjunctions within supernatural setting (Ouija board, extrasensory perception, psychokinesis, precognition and strange occurrence). Previous studies investigating the effects of context on susceptibility to conjunction have used these items (see Dagnall et al., 2014 \& 2016). An example is, 'Andrew often sits by the telephone at work. Just as he is thinking about his friend (Elaine), she rings. What is the most likely outcome? Elaine rang because Andrew was thinking about her (b) Andrew was thinking about Elaine because she was about to ring (c) Elaine rang'.

In total twenty-five items assessed probabilistic reasoning. There were five items within each problem category. Hence, scores for each problem type ranged from 0 to 5 , with higher 
scores indicating good reasoning ability. To aid comparisons, scores appear also as proportions $(0 \%$ to $100 \%)$.

Random selection allocated one item from each problem type into one of five sections. Counterbalancing of item order within sections controlled for potential order effects. After reading each problem, participants indicated the most probable outcome from the range of presented alternatives.

\section{Conspiracy Measures}

There is no single agreed measure of conspiracism. Hence, two scales assessed endorsement of conspiracies. The use of multiple measures ensured construct measurement adequacy and functioned as a validity check.

\section{Generic Conspiracist Beliefs (GCB)}

The GCB is a 15-item unidimensional measure of conspiracist ideation. Questions appear as statements (e.g., 'Secret organizations communicate with extra-terrestrials, but keep this fact from the public'). Participants respond to each item via a five-point Likert scale (1: definitely not true; 2: probably not true; 3: not sure/cannot decide; 4: probably true; 5: definitely true). The GCB demonstrates established psychometric properties. Particularly, it possesses excellent internal reliability $(\alpha=.95)$ and validity (content, criterion-related, convergent and discriminant) (Brotherton et al., 2013). In the current study, internal reliability was high $(\alpha=$ $.89)$.

General Measure of Conspiracism (GMC) (Drinkwater et al., 2012)

Five items measured the degree to which respondents believed that conspiracy theories accurately depict real life events and contain truthful information (e.g., 'I have heard several conspiracy theories which I believe to be true'; Drinkwater et al., 2012). Responses were measured on a 7 -point Likert scale $(1=$ strongly disagree, $4=$ neither disagree nor agree, $7=$ strongly agree). To control for response bias, the measure contains two reversed items. The 
GMB score is the average rating for the five items, thus scores range from 1.00 to 7.00. Psychometric evaluation indicates that the GMC possesses validity and good internal reliability (Dagnall, Drinkwater, Parker, Denovan \& Parton, 2015). In this study internal reliability was $\operatorname{high}(\alpha=.86)$.

Revised Paranormal Belief Scale (RPBS) (Tobacyk \& Milford, 1983, Tobacyk, 1988)

The RPBS is a self-report measure, which contains 26 items and assesses belief in the paranormal. It is the most widely used measure of paranormal belief (Goulding \& Parker, 2001). Within the RPBS, questions appear as statements (e.g., 'There is a devil'). Participants respond to each item via completion of a seven-point Likert scale, ranging from 1 (strongly disagree) to 7 (strongly agree). Items examine seven facets of belief: precognition, psi, traditional religious beliefs, spiritualism, witchcraft, superstition, and extraordinary life forms. The RPBS overall possesses satisfactory reliability and adequate validity (Tobacyk, 2004). Thus, researchers generally regard the RPBS as a satisfactory measure of belief in the paranormal (Tobacyk, 2004). However, sub-scale evaluations question the psychometric properties of individual dimensions (Cardena, Palmer, \& Marcusson-Clavertz, 2015). Consequently, Lange, Irwin, and Houran (2000) purified the RPBS. This process identified an enhanced two-factor solution based on belief function. This comprised New Age Philosophy (NAP) (11-items assesses belief in psi and survival of bodily death) and Traditional Paranormal Belief (TPB) (5-items measure belief in concepts, such as the devil, witchcraft, heaven and hell) (Cardena et al., 2015). These dimensions reflect belief functions (individual vs. social) (Lange et al., 2000). NAP at the personal level imparts control over external events (Irwin, 1992), whilst TPB regulates social/cultural factors (Goode, 2000).

Generation of NAP and TPB scores requires item recoding (0-6) (Lange et al., 2000). RPBS total following transformation range from $0-156$, higher scores representing greater belief in the belief in the paranormal. Scores on the purified scale range from 6.85 to 47 for 
NAP and 11.16 to 43.24 TPB. The RPBS $(\alpha=.94)$ possessed good internal reliability, as did $\operatorname{NAP}(\alpha=.91)$ and $\operatorname{TPB}(\alpha=.81)$.

\section{Procedure}

Prospective participants read the study brief prior to agreeing to take part. After providing informed consent, participants received the materials booklet. Instructions asked participants to take their time and answer questions as openly and honestly as possible. The booklet contained four sections: personal information (always completed first), problems, conspiracy measures and belief in the paranormal (counter-balancing rotated the order in which participants completed scale measures). On completion of the booklet, participants were debriefed. The researcher obtained ethical approval for the study as part of a research project examining the relationship between anomalous beliefs and cognitive-perceptual measures.

\section{RESULTS}

\section{Inter-measure correlations}

Following data screening, means, standard deviations and bivariate correlations were calculated. The conspiracy measures (GCB and GMC) correlated positively with each other, $r$ $(244)=.64, p<.001$, and belief in the paranormal; GCB and RPBS, $r(244)=.45, p<.001$; GMC and RPBS, $r(244)=.47, p<.001$. Both relationships were similar in size and within the moderate range (Cohen, 1992). 


\section{Probabilistic Reasoning Tasks Descriptive Statistics}

Probabilistic reasoning task scores were calculated for perception of randomness and conjunction manipulations (standard, every day, conspiracy and paranormal). These appear in Table 2 presented as means and proportions alongside inter-problem correlations. Positive correlations were evident between problem types, with the exception of perception of randomness and conjunctions set in a conspiratorial context, $r(244)=.03, p=.320$.

INSERT TABLE 2 HERE

\section{Conjunction and Framing Effects}

A further set of correlations (see table 3) revealed significant negative associations between conspiracy measures (GBC and GMC) and conjunction manipulations (standard, every day, conspiracy and paranormal); relationships with perception of randomness, however, were not significant. In comparison, belief in the paranormal correlated negatively with all probabilistic reasoning tasks.

Framing manipulation did not influence the relationship between conspiracy and conjunction error. Consideration of the eight correlations revealed no statistically significant difference. Particularly, between the lowest (GMC and standard conjunction, $r=-.15$ ) and highest (GMC and paranormal conjunction, $r=-.26$ ) observed correlations, $r$ difference $=.11$ $(N=246), 95 \%$ confidence interval (CI) $[-.03, .25]$ (CI for overlapping correlations calculated in accordance with Zou, 2007).

Contrastingly, within the four correlations between belief in the paranormal (RPBS) and the conjunction manipulations, there was a statistically significantly difference. The difference between the lowest $(r=-.16)$ and highest $(r=-.46)$ observed correlations was significant, $r$ difference $=.26(N=246), 95 \%$ CI $[.12, .34]$. 
INSERT TABLE 3 HERE

\section{General Analytical Strategy}

Noting the problem encountered by Brotherton and French (2014) in study 1, where high endorsement of a single item concerning the death of Princess Diana potentially influenced the results, the preference in the current study was to assess propensity to universal conspiratorial ideation. The authors were aware that Brotherton and French (2014) used the GCB in study 2 in attempt to reduce the likelihood of particular events biasing the results. This measure, however, refers to governments, scientists/experimentation and powerful groups/individuals. Hence, Model testing used the GCM because it is a brief, context-free measure of general conspiracy endorsement. Precisely, the GCM indexes overall tendency to endorse conspiracy theories without explicit reference to particular groups, individuals, plots, organisations or events. Analyses were, however, performed in relation to the GCB as a validity check for the relationships observed using the GCM.

Analysis progressed through a number of discrete stages. Prior to model evaluation, confirmatory factor analysis evaluated measurement model adequacy and scale composite internal reliability was determined. Subsequently, structural equation modelling (SEM) tested structural relationships between components of statistical bias (perception of randomness, PR; and conjunction fallacy, CF), and anomalistic beliefs (paranormal beliefs and conspiracy).

Four models tested the hypothesis that statistical biases (PR and CF) were correlated, but differentially related to belief in the paranormal (PB) and general conspiracism (GMC). Model 1 tested the association between PR and CF, while examining whether PR predicted PB, and CF predicted GMC. Model 2 reversed the structural paths between PR-PB and CF-GMC to ascertain whether PB and GMC more strongly predicted statistical bias. Model 3 examined 
the correlation between PR and CF, while evaluating whether PR predicted GMC, and CF predicted PB. Model 4 reversed structural paths between PR-GMC and CF-PB to examine if PB and GMC more strongly predict statistical bias. For validity purposes, Model 1 and Model 3 were replicated (referred to as Model 5 and Model 6) and GCB was tested in relation to statistical bias rather than GMC.

To evaluate model fit the chi-square statistic $\left(\chi^{2}\right)$, Comparative Fit Index (CFI), Incremental Fit Index (IFI), and Root-Mean-Square Error of Approximation (RMSEA) (Hu \& Bentler, 1999) were used. CFI and IFI values of .86 suggest marginal fit (e.g., Bong, Woo, \& Shin, 2013), values of .90 are satisfactory, and values greater than .95 represent good fit (Hu \& Bentler, 1999). RMSEA values of .05 indicate good fit, values between .06-.08 indicate satisfactory fit, and between .08 to .10 suggest marginal errors of approximation (Browne \& Cudeck, 1993). The 90\% confidence interval (CI) was included when reporting RMSEA. To facilitate model comparison, analysis used Akaike's Information Criterion (AIC; Akaike, 1974), with lower values indicating superior fit.

\section{Confirmatory factor analysis}

Confirmatory factor analysis involved testing a priori factor solutions for the RPBS, statistical bias problems, the GMC, and the GCB. Previous research defined scale structure. The RPBS possesses a correlated two-factor solution consisting of New Age Philosophy and Traditional Paranormal Beliefs (Lange et al., 2000); statistical bias includes a correlated two-factor solution, comprising PR and CF (Dagnall et al., 2016); and GMC encompasses a single factor (Drinkwater et al., 2012). GCB possesses a five-factor solution consisting of government malfeasance (GM), extra-terrestrial cover-up (EC), malevolent global conspiracies (MG), personal wellbeing (PW), and control of information (CI) factors (Brotherton et al., 2013). 
Analysis indicated unsatisfactory fit for the RPBS solution, $\chi^{2}(99, N=246)=575.21$, $p<.001, \mathrm{CFI}=.82, \mathrm{IFI}=.82, \mathrm{RMSEA}=.13(\mathrm{CI}$ of .12 to .15$)$. This finding was consistent with previous research indicating that the two-factor solution typically yields marginal to unsatisfactory fit (Dagnall et al., 2016). Inspection of modification indices suggested that model fit would be improved, $\chi^{2}(96, N=246)=338.49, p<.001, \mathrm{CFI}=.91$, IFI $=.91$, RMSEA $=.10(\mathrm{CI}$ of .09 to .11$)$, by allowing within-factor error terms to correlate. Correlating these error terms, despite the risk of chance capitalization (MacCallum, Roznowski, \& Necowitz, 1992), facilitated interpretation because item combinations corresponded with subscales located within the original RPBS 7-factor solution (psi, spiritualism, superstition, witchcraft, precognition, traditional religious belief, and extraordinary life forms) (Tobacyk, 2004). Precisely, psi (items 2, 9, and 16), spiritualism (items 5 and 12), precognition (items 7 and 14) and traditional religious belief (items 8 and 22). Byrne (2016) recommends avoidance of correlating within-factor error terms without a clear rationale; in this instance, clear justification existed.

The correlated two-factor model for statistical bias provided satisfactory data-model fit on all criteria but CFI and IFI, $\chi^{2}(34, N=246)=57.02, p=.008, \mathrm{CFI}=.78, \mathrm{IFI}=.81$, RMSEA $=.05$ (CI of .03 to .07). Factor loadings revealed that Problem 4 loaded poorly onto PR (loading of .21). Removal of this item resulted in superior fit, $\chi^{2}(26, N=246)=22.09, p=.68, \mathrm{CFI}=$ $1.0, \mathrm{IFI}=1.0, \mathrm{RMSEA}=.01(\mathrm{CI}$ of .01 to .04$)$. Further analysis suggested that Problem $1 \mathrm{did}$ not load significantly onto the PR factor $(p=.060)$; however, to preserve construct breadth the item was retained; removal of this item would not substantially improve data-model fit. The one-factor model for GMC indicated good fit, $\chi^{2}(4, N=246)=9.67, p=.050, \mathrm{CFI}=.99$, IFI $=.99$, RMSEA $=.07$ (CI of .02 to .09). The five-factor solution for GCB reported good overall model fit, $\chi^{2}(85, N=246)=184.12, p<.001, \mathrm{CFI}=.94, \mathrm{IFI}=.94, \mathrm{RMSEA}=.07(\mathrm{CI}$ of .06 to .08). 
Overall, results specified that the theoretically driven factor models for paranormal beliefs, statistical bias, and conspiracy were adequate. Furthermore, all factor loadings but one (Problem 1) were positive and statistically significant. The majority of items possessed factor loadings greater than the minimum threshold of .32 (Tabachnick \& Fidell, 2001).

\section{Composite reliability}

Within a latent modelling context, traditional measures of internal reliability (i.e. Cronbach's $\alpha$ ) often over or underestimate scale reliability. Hence, composite reliability provides a more rigorous assessment of internal consistency (Raykov, 2002) with values above .60 considered satisfactory (Diamantopoulos \& Siguaw, 2000). Results for the statistical bias and general conspiracy measure indicated satisfactory composite reliability $(\rho c=.85$ and $\rho c=.86$ respectively). Traditional Paranormal Beliefs and New Age Philosophy demonstrated also satisfactory composite reliability ( $\rho c=.80$ and $\rho c=.91$ respectively), as did GCB factors (GM $\rho c=.77, \mathrm{EC} \rho c=.75, \mathrm{MG} \rho c=.80, \mathrm{PW} \rho c=.68, \mathrm{CI} \rho c=.67)$.

\section{Model evaluation}

Fit indices for Model 1 (see figure 1) indicated satisfactory data-model fit, $\chi^{2}(392, N=246)=$ $730.77, p<.001, \mathrm{CFI}=.90, \mathrm{IFI}=.90, \mathrm{RMSEA}=.05(\mathrm{CI}$ of .05 to .06$)$. Structural paths revealed PR had a significant negative effect on PB factors of TPB $(\beta=-.34, p=.007)$ and NAP $(\beta=-$ $.33, p=.007)$, and $\mathrm{CF}$ had a significant negative effect on $\operatorname{GMC}(\beta=-.30, p=.014)$. In addition, PR demonstrated a significant moderate positive correlation with $\mathrm{CF}(r=.44, p=.020)$.

In comparison to Model 1, Model 2 demonstrated marginal fit to these data, $\chi^{2}$ (393, $N$ $=246)=757.74, p<.001, \mathrm{CFI}=.89, \mathrm{IFI}=.89, \mathrm{RMSEA}=.06(\mathrm{CI}$ of .05 to .07$)$. Structural paths indicated that neither TPB, nor NAP had a significant effect on PR $(\beta=-.32, p=.512 ; \beta$ 
$=.05, p=.910$ respectively). GMC had a significant negative effect on $\mathrm{CF}(\beta=-.25, p=.019)$, however, this effect following relationship reversal was weaker.

Fit indices for Model 3 (see figure 2) advised acceptable model fit, $\chi^{2}(392, N=246)=$ 739.82, $p<.001, \mathrm{CFI}=.90, \mathrm{IFI}=.90, \mathrm{RMSEA}=.06(\mathrm{CI}$ of .05 to .07$)$. Consideration of structural paths showed that CF had a significant negative effect on TPB $(\beta=-.28, p=.024)$ and NAP $(\beta=-.28, p=.023)$. Nevertheless, relationships were weaker than for PR and paranormal belief factors (TPB and NAP) (c.f., Model 1). Moreover, PR did not have a significant effect on GMC $(\beta=-.20, p=.051)$. Similar to Model $1, \mathrm{PR}$ and CF possessed a significant moderate positive correlation $(r=.48, p=.020)$.

Model 4 demonstrated marginal fit on all indices, $\chi^{2}(393, N=246)=768.43, p<.001$, $\mathrm{CFI}=.89, \mathrm{IFI}=.89, \mathrm{RMSEA}=.06(\mathrm{CI}$ of .05 to .07$)$. Inspection of structural paths revealed that neither TPB, nor NAP had a significant effect on $\mathrm{CF}(\beta=-.01, p=.977 ; \beta=-.14, p=.763$ respectively). GMC did not have a significant effect on $\operatorname{PR}(\beta=-.10, p=.354)$.

For Model 5, fit was marginal for all indices but RMSEA, $\chi^{2}(724, N=246)=1370.58$, $p<.001, \mathrm{CFI}=.86, \mathrm{IFI}=.86, \mathrm{RMSEA}=.06(\mathrm{CI}$ of .05 to .06$)$. However, structural relationships were similar to Model 1 . Specifically, CF had a significant negative effect on conspiracy (GCB) $(\beta=-.43, p=.003)$, and PR had a significant negative effect on TPB $(\beta=-$ $.34, p=.005)$ and NAP $(\beta=-.31, p=.006)$. Data-model fit was unsatisfactory for CFI, marginal for IFI, and acceptable for RMSEA for Model 6, $\chi^{2}(724, N=246)=1387.79, p<.001, \mathrm{CFI}=$ $.85, \mathrm{IFI}=.86, \mathrm{RMSEA}=.06(\mathrm{CI}$ of .05 to .06$)$. However, similar relationships to Model 3 were observed, as PR did not have a significant effect on conspiracy (GCB) $(\beta=-.27, p=.117)$, and CF had a significant negative effect on TPB $(\beta=-.28, p=.020)$ and NAP $(\beta=-.29, p=.020)$.

Comparison of AIC values suggested that Model 1 provided superior data fit (Burnham, \& Anderson, 2002). AIC for Model $1(\mathrm{AIC}=936.77)$ was lower than Model $2(\mathrm{AIC}=961.74)$, Model $3(\mathrm{AIC}=945.82)$, and Model $4(\mathrm{AIC}=972.43)$. Collectively, results supported the 
notion that whilst related (significantly positively correlated), PR and CF possess distinct, differential relationships with PB and GMC. Explicitly, PR had a significant negative effect on PB factors, but not GMC. CF had a significant negative effect on PB and GMC, the relationship was stronger in relation to GMC. Results for Model 5 and Model 6 further support the results and the direction of relationships observed between statistical bias, paranormal belief and conspiracy in Models 1 to 4 . The superior fit of Model 1 and Model 3 in comparison with Model 2 and Model 4, alongside stronger structural paths, supported the hypothesised inverse relationship between statistical bias and belief (PB and GMC).

INSERT FIGURE 1 HERE

INSERT FIGURE 2 HERE

\section{Partial Correlations}

For completeness, partial correlation assessed the unique contribution of each component of statistical bias to belief types. In the case of conspiracy, CF (controlling for PR) significantly negatively correlated with GMC, $r(243)=-.13, p=.020$; PR (controlling for CF) was not related to GMC, $r(243)=-.04, p=.518$. For belief in the paranormal, PR (controlling for CF) significantly negatively correlated with RPBS, $r(243)=-.21, p=.001 ; \mathrm{CF}$ (controlling for PR) was not associated with RPBS, $r(243)=-.09, p=.144$.

\section{DISCUSSION}

As predicted, components of statistical bias were differentially related with endorsement of unconventional/alternative beliefs. Explicitly, conjunction error most strongly predicted 
conspiratorial ideation, whilst perception of randomness most strongly predicted belief in the paranormal. These findings contradicted the notion that anomalous beliefs (i.e., conspiracism and belief in the paranormal), by virtue of possession of common characteristics, relate similarly to conjunction error (Brotherton \& French, 2014). This assumption is an overgeneralisation, which ignores the complex, varied nature of unusual/unconventional beliefs. Findings indicated that although conspiratorial and paranormal beliefs share surface features, such as defiance of conventional understanding of reality, they are characterised by construct unique characteristics that serve to distinguish them. Importantly, variations affect bias susceptibility.

Previous work supports this conclusion. For example, the finding that endorsement of conspiracy and belief in the paranormal share only modest variance (Darwin et al., 2011; Dagnall et al., 2016; Drinkwater, et al., 2012; Lobato, et al., 2014; Swami et al., 2011). Thus, rather than representing sub-categories of anomalistic belief, the variables are best viewed as overlapping, but distinct constructs. Congruently, within the present study, relationships between conspiracy and paranormal measures were within the weak to moderate $(.30-.50)$ range. Accordingly, conspiratorial thinking correlated with proneness to conjunction error, but not perception of randomness. Whilst, belief in the paranormal related to both components of statistical bias.

Furthermore, SEM analysis and partial correlation revealed that the belief in the paranormal and conjunction error association arose largely from variance explained by perception of randomness. This finding was consistent with the previously reported observation that conjunction tasks, in the context of paranormal belief, indirectly index misperception of randomness (see Dagnall et al., 2016, Rogers, 2014). Indeed, controlling for conjunction had little effect on the correlation between perception of randomness and paranormal belief. 
Contrastingly, the association between conjunction and belief in the paranormal became insignificant when analysis controlled for perception of randomness.

The observation of a weak relationship between belief in the paranormal and propensity to conjunction error paralleled previous studies (Dagnall et al., 2014, 2016). Pertinently, it concurred with Brotherton and French (2014), who noted that only unsophisticated analysis based on median splits (believers vs. nonbelievers) produced significant effects. Within the present study, the inclusion of a measure of perception of randomness enabled more refined appreciation of the relative impact and importance of conjunction. Thus, whilst conjunction was associated with belief in the paranormal, perception of randomness demonstrated a stronger relationship.

More generally, the existence of a significant relationship between belief in the paranormal and susceptibility to conjunction fallacy agrees with the work of Rogers and colleagues $(2009,2011,2016)$. It is consistent also with Dagnall et al. $(2014,2016)$, who reported weak effects, which vary as a function of belief type. In the context of the Revised Paranormal Belief Scale (RPBS), significant effects are typically found with the traditional paranormal belief dimension.

With regard to conspiracy, conjunction-framing manipulations produced relatively minor variations in relationship strength. This supported Brotherton and French's (2014) assertion that conspiratorial ideation is associated with a domain-general susceptibility to conjunction error. Framing, however, influenced the relationship between belief in the paranormal and conjunction. Whilst, paranormal conjunctions were generally easier to solve, performance declined as the level of paranormal belief increased. This finding supported previous work by Dagnall et al. (2016). This outcome requires cautious interpretation because framing problems in a paranormal context, potentially conflates problem-solving ability with 
paranormal belief. Hence, the usefulness of the paranormal manipulation needs further assessment and development.

One possibility is to compare performance on a range of paranormal beliefs (extrasensory perception, psychokinesis, hauntings, astrology, etc.). Believers' ability to solve conjunctions should then vary as a degree of belief in particular paranormal phenomena. This will facilitate a more precise understanding of the relationship between statistical bias and belief. Overall, measures may obscure important variations and effects. Certainly, framing manipulations based on overall paranormal belief produces a crude insensitive measurement tool.

Having established that the relationship between conspiratorial ideation and susceptibility to conjunction is robust, future studies may expand research to consider premise/information importance. Recent work in the area of paranormal belief by Rogers et al. (2016) reported that more errors occurred for confirmatory (vs. disconfirmatory) conjunctions. Whilst, they noted that event type (paranormal vs. non-paranormal) had no effect on error rate it would be worthwhile investigating whether conspiracy premise content influences proneness to conjunction errors. Firstly, by establishing if conspiracy theory endorsement is more likely when the evidence inherent within the first constituent inductively confirms the second (vs. disconfirms). This would appear to be highly consistent with the nature of conspiracy theories. Proof for the veracity of a conspiracy theory derives often from perceived information relatedness. If ' $A$ ' supports the notion that the official explanation is untrue, it is wrongly regarded as supportive evidence for the alternative conspiracy theory, 'B'. If the associated information is consistent with the stated premise then presumably level of endorsement should increase. Contrastingly, if the information contradicts the premise conjunction error should reduce. Past work has demonstrated that confirmation relations affect probability judgments (Tentori, \& Crupi, 2012). 
Secondly, manipulation of conspiracy consequence could occur. Research details that participants are more likely to endorse conspiracies associated with large (vs. negligible consequences) (LeBoeuf, \& Norton, 2012), and conspiracies associated with major event minor (vs. minor) events (Leman, \& Cinnirella, 2007). Clearly, these factors ought to influence the strength of the relationship between conspiracy endorsement and susceptibility to conjunction error. Individuals will be more likely to endorse conjunction scenarios where the consequences are major (i.e., an assassination results in all-out war vs. minor trade sanctions) and the event significant (assassinated figure is the leader of a major world power vs. a small distant country).

Finally, results advocate the need for further work investigating potential interactions between belief types and propensity to heuristic bias. Preceding studies have focussed on general paranormal belief and more recently conspiracy theory. Broad belief classification may obfuscate and obscure important nuanced relationships. Individual beliefs by virtue of their structure and content may increase susceptibility to particular forms of bias. This supposition is consistent with Dagnall et al.'s $(2014,2016)$ finding that conjunction error is more strongly correlated with TPB. TPB includes concepts such as the devil, witchcraft, heaven and hell, and serves to regulate social/cultural factors (Goode, 2000). Similarly, Rogers et al. (2016) noted that extrasensory perception and psychokinesis were associated with heightened susceptibility to generic conjunction fallacy. In this context, the nature of superstitious beliefs may predispose an association with conjunction error. Similar to conspiracy, justifications for good/bad luck often refer to supporting evidence/premises. For instance, good/bad luck (A) occurred because of a certain event or occurrence (B). Contrastingly, several other paranormal phenomena derive principally from the designation of causation/meaning to random events (extrasensory perception, astrology, etc.).

Considering these examples, a key factor may be whether believers attribute causation to general forces, or definite factors. For instance, people may believe astrology can predict 
their future (this would generally arise from misperception of randomness). However, if they ascribe an outcome to a precise agent, the bias emphasis moves towards conjunction error (i.e., seeing a psychic, having a reading and then encountering good/bad fortune). Thus, generally, conjunction is most likely to occur when explicit instances provide support for general laws and principles. This postulation is consistent with the observation that belief in the paranormal correlates with both misperception of randomness and propensity to conjunction errors and explains why the relationship of the latter to paranormal belief is weaker. Thus, causal emphasis may influence bias susceptibility. Relatedly, because recent research reports an association between conspiratorial ideation and intentionality bias (the inclination to see purpose in the movements of both animate and inanimate objects) (Brotherton \& French, 2015) future study may wish to consider the degree to which intentionality and statistical bias are related.

The tendency to focus on general beliefs reflects the nature of the measures rather than research strategy. In the case of paranormal beliefs, the two main scales (RPBS and Australian Sheep Goat Scale) act typically as general measures. They also function best at the global level of measurement. This is because the underlying subscales are either psychometrically questionable, and/or lack construct breadth. An example of this within the RPBS is psi. The sub-scale comprises three items indexing (PK) psychokinesis and a single question about mind reading. Whilst related, these represent distinct paranormal phenomena. Similarly, extrasensory perception is a generic term denoting various psychic abilities (telepathy, clairvoyance, clairaudience, precognition, remote viewing, etc.), which differ greatly. Hence, the study of discrete beliefs would further inform and facilitate understanding of reasoning and propensity towards statistical bias. 


\section{Conclusion}

Whilst anomalous beliefs shared common characteristics, belief unique features effected susceptibility to components of statistical bias. Hence, proneness to conjunction error more strongly predicted endorsement of conspiracy and PR related more strongly to PB (the relationship with conjunction was weaker and indirect). This indicated that belief structure, nature, content and function moderated relationships. Additionally, whilst framing effected overall task solution rate, it had no significant influence on relationships between conspiratorial ideation and conjunction error. This finding supported the notion that endorsement of conspiracy theories was associated with domain-general susceptibility to conjunction error. Conversely, a framing effect occurred for paranormal beliefs; although paranormal conjunctions were easier to solve, performance declined as level of paranormal belief increased. In conclusion, the present study found no support for the view that susceptibility to conjunction generally predicted anomalous beliefs. 


\section{REFERENCES}

Akaike, H. (1974). A new look at the statistical model identification. IEEE transactions on automatic control, 19: 716-723. DOI:10.1109/TAC.1974.1100705

Arnott, D. (1998). A taxonomy of decision biases. Monash University, School of Information Management and Systems, Caulfield.

Arnott, D. (2006). Cognitive biases and decision support systems development: a design science approach. Information Systems Journal, 16, 55-78. DOI:10.1111/j.13652575.2006.00208.x

Barron, D., Morgan, K., Towell, T., Altemeyer, B., \& Swami, V. (2014). Associations between schizotypy and belief in conspiracist ideation. Personality and Individual Differences, 70, 156-159. DOI: 10.1016/j.paid.2014.06.040

Blackmore, S., \& Troscianko, T. (1985). Belief in the paranormal: Probability judgements, illusory control, and the 'chance baseline shift'. British Journal of Psychology, 76, 459468. DOI: 10.1111/j.2044-8295.1985.tb01969.x

Bong, M., Woo, Y., \& Shin, J. (2013). Do students distinguish between different types of performance goals? The Journal of Experimental Education, 81, 464-489. DOI:10.1080/00220973.2012.745464.

Broad, C. D. (1949). The relevance of psychical research to philosophy. Philosophy, 24(91), 291-309.

Brotherton, R., \& French, C.C. (2014). Belief in conspiracy theories and susceptibility to the conjunction fallacy. Applied Cognitive Psychology, 28, 238-248. DOI: 10.1002/acp.2995

Brotherton, R., \& French, C.C (2015). Intention seekers: Conspiracist ideation and biased attributions of intentionality. PLoS ONE 10: e0124125. DOI: 10.1371/journal.pone. 0124125 
Brotherton, R., French, C. C., \& Pickering, A. D. (2013). Measuring belief in conspiracy theories: the generic conspiracist beliefs scale. Frontiers in Psychology, 4, 279. DOI: 10.3389/fpsyg.2013.00279

Browne, M. W., \& Cudeck, R. (1993). Alternative ways of assessing model fit. In Bollen, K. A. and Long, J. S. (eds.) Testing Structural Equation Models, pp 136-162. Newbury Park, CA: Sage.

Brugger, P., \& Taylor, K. I. (2003). ESP: Extrasensory perception or effect of subjective probability? Journal of Consciousness Studies, 10, 221-246.

Burnham, K. P., \& Anderson, D. R. (2002). Model selection and multimodel inference: a practical information-theoretic approach. Springer, New York.

Byrne, B. M. (2016). Structural equation modeling with AMOS: Basic concepts, applications, and programming. Routledge.

Cardena, E., Palmer, J., \& Marcusson-Clavertz, D. (2015). Parapsychology: A handbook for the 21st century. McFarland.

Cohen, J. (1992). A power primer. Psychological Bulletin, 112, 155-159. DOI: 10.1037/00332909.112.1.155

Dagnall, N., Drinkwater, K., Denovan, A., Parker, A., \& Rowley, K. (2016). Misperception of chance, conjunction, framing effects and belief in the paranormal: a further evaluation. Applied Cognitive Psychology, 30, 409-419. DOI: 10.1002/acp.3217

Dagnall, N., Drinkwater, K., Parker A., Denovan, A., \& Parton, M. (2015). Conspiracy theory and cognitive style: a worldview. Frontiers in Psychology, 6. http://dx.doi.org/10.3389/fpsyg.2015.00206/acp.3057

Dagnall, N., Drinkwater, K., Parker, A., \& Rowley, K. (2014). Misperception of chance, conjunction, belief in the paranormal and reality testing: a reappraisal. Applied Cognitive Psychology, 28, 711-719. 
DOI:10.1002http://dx.doi.org/10.3389/fpsyg.2016.01045

Dagnall, N., Parker, A., \& Munley, G. (2007). Paranormal belief and reasoning. Personality and Individual Differences, 43, 1406-1415. DOI:10.1016/j.paid.2007.04.017

Darwin, H., Neave, N., \& Holmes, J. (2011). Belief in conspiracy theories. The role of paranormal belief, paranoid ideation and schizotypy. Personality and Individual Differences, 50, 1289-1293. DOI: 10.1016/j.paid.2011.02.027

Diamantopoulos, A., \& Siguaw, J. A. (2000). Introducing LISREL: A guide for the uninitiated. Leicester: Sage.

Dieguez, S., Wagner-Egger, P., \& Gauvrit, N. (2015). Nothing happens by accident, or does it? A low prior for randomness does not explain belief in conspiracy theories. Psychological Science, 26, 1762-1770. DOI: 10.1177/0956797615598740

Douglas, K. M., \& Sutton, R. M. (2011). Does it take one to know one? Endorsement of conspiracy theories is influenced by personal willingness to conspire. British Journal of Social Psychology, 50, 544-552. DOI: 10.1111/j.2044-8309.2010.02018.x

Drinkwater, K., Dagnall, N., \& Parker, A. (2012). Reality testing, conspiracy theories, and paranormal beliefs. Journal of Parapsychology, 76, 57-78.

George, D., \& Mallery, P. (2003). SPSS for Windows step by step: A simple guide and reference. 11.0 update (4 ${ }^{\text {th }}$ Ed.), Boston: Allyn \& Bacon.

Goode, E. (2000). Paranormal beliefs: A sociological introduction. Prospect Heights, IL: Waveland Press.

Goulding, A., \& Parker, A. (2001). Finding psi in the paranormal: Psychometric measures used in research on paranormal beliefs/experiences and in research on psi-ability. European Journal of Parapsychology, 16, 73-101. 
Hu, L., \& Bentler, P. M. (1999). Cutoff criteria for fit indexes in covariance structure analysis: Conventional criteria versus new alternatives. Structural Equation Modeling: A Multidisciplinary Journal, 6, 1-55. DOI: 10.1080/10705519909540118.

Imhoff, R., \& Bruder, M. (2014). Speaking (un-) truth to power: Conspiracy mentality as a generalised political attitude. European Journal of Personality, 28, 25-43. DOI: 10.1002/per.1930

Irwin, H. J. (1992). Origins and functions of paranormal belief: the role of childhood trauma and interpersonal control. Journal of the American Society for Psychical Research, 86, $199-208$.

Irwin, H. J. (2004). Reality testing and the formation of paranormal beliefs: A constructive replication. Journal of the Society for Psychical Research, 68, 143-152.

Lange, R., Irwin, H. J., \& Houran, J. (2000). Top-down purification of Tobacyk's Revised Paranormal Belief Scale. Personality and Individual Differences, 29, 131-156. DOI: 10.1016/S0191-8869(99)00183-X

Leman, P. J., \& Cinnirella, M. (2007). A major event has a major cause: Evidence for the role of heuristics in reasoning about conspiracy theories. Social Psychological Review, 9, $18-28$.

LeBoeuf, R. A., \& Norton, M. I. (2012). Consequence-cause matching: Looking to the consequences of events to infer their causes. Journal of Consumer Research, 39, 128141. DOI: $10.1086 / 662372$

Lobato, E., Mendoza, J., Sims, V., \& Chin, M. (2014). Examining the relationship between conspiracy theories, paranormal beliefs, and pseudoscience acceptance among a university population. Applied Cognitive Psychology, 28, 617-625. DOI: 10.1002/acp.3042 
MacCallum, R. C., Roznowski, M., \& Necowitz, L. B. (1992). Model modification in covariance structure analysis: The problem of capitalization on chance. Psychological Bulletin, 111, 490-504. DOI: 10.1037/0033-2909.111.3.490

Nickell, J. (2009). Return to Roswell. Skeptical Inquirer, 33(1), 10-12.

Raykov, T. (2002). Analytic estimation of standard error and confidence interval for scale reliability. Multivariate Behavioral Research, 37, 89-103. DOI: 10.1207/S15327906MBR3701_04.

Rogers, P. (2014). Paranormal believers' proneness to probabilistic reasoning biases, in Aberrant Beliefs and Reasoning, ed. N. D. Galbraith (Hove: Psychology Press), 114131.

Rogers, P., Davis, T., \& Fisk, J. E. (2009). Paranormal belief and susceptibility to the conjunction fallacy. Applied Cognitive Psychology, 23, 524-542. DOI: 10.1002/acp. 1472

Rogers, P., Fisk, J. E., \& Wiltshire, D. (2011). Paranormal belief and the conjunction fallacy: Controlling for temporal relatedness and potential surprise differentials in component events. Applied Cognitive Psychology, 25, 692-702. DOI: 10.1002/acp.1732

Rogers, P., Fisk, J. E., \& Lowrie, E. (2016). Paranormal believers' susceptibility to confirmatory versus disconfirmatory conjunctions. Applied Cognitive Psychology, Online Version of Record published before inclusion in an issue. DOI: 10.1002/acp.3222

Sunstein, C. R., \& Vermeule, A. (2009). Conspiracy theories: causes and cures. Journal of Political Philosophy, 17, 202-227. DOI: 10.1111/j.1467-9760.2008.00325.x

Swami, V., Coles, R., Stieger, S., Pietschnig, J., Furnham, A., Rehim, S., \& Voracek, M. (2011). Conspiracist ideation in Britain and Austria: Evidence of a monological belief system and associations between individual psychological differences and real-world 
and fictitious conspiracy theories. British Journal of Psychology, 102, 443-463. DOI:10.1111/j.2044-8295.2010.02004.X

Tabachnick, B. G., \& Fidell, L. S. (2001). Using multivariate analysis. California State University Northridge: Harper Collins College Publishers.

Tanaka, J. S. (1987). 'How big is big enough?': Sample size and goodness of fit in structural equation models with latent variables. Child Development, 134-146. DOI: $10.2307 / 1130296$

Tentori, K., \& Crupi, V. (2012). How the conjunction fallacy is tied to probabilistic confirmation: Some remarks on Schupbach (2009). Synthese, 184, 3-12. DOI: 10.1007/s11229-009-9701-y

Tentori, K., Crupi, V., \& Russo, S. (2013). On the determinants of the conjunction fallacy: Probability versus inductive confirmation. Journal of Experimental Psychology: General, 142, 235-255. DOI:10.1037/a0028770.

Thalbourne, M. A., \& Delin, P. S. (1993). A new instrument for measuring the sheep-goat variable: Its psychometric properties and factor structure. Journal of the Society for Psychical Research, 59, 172-186.

Thomas, D. (1995). The Roswell incident and project Mogul. Skeptical Inquirer, 19(4), 15-18. Tobacyk, J. (1988). A revised paranormal belief scale. Unpublished manuscript, Rushton, LA: Louisiana Tech University.

Tobacyk, J. J. (2004). A revised paranormal belief scale. The International Journal of Transpersonal Studies, 23, 94-99.

Tobacyk, J., \& Milford, G. (1983). Belief in paranormal phenomena: Assessment instrument development and implications for personality functioning. Journal of Personality and Social Psychology, 44, 1029-1037. DOI:10.1037/0022-3514.44.5.1029 
Tversky, A., \& Kahneman, D. (1982). Evidential impact of base rates. In D. Kahneman, P. Slovic \& A. Tversky (Eds.), Judgement under uncertainty: Heuristics and biases (pp. 153-160). New York: Cambridge University Press. DOI:10.1017/CBO9780511809477.011

Tversky, A., \& Kahneman, D. (1983). Extensional versus intuitive reasoning: The conjunction fallacy in probability judgement. Psychological Review, 90, 293-315. DOI:10.1037/0033-295X.90.4.293

Zou, G. Y. (2007). Toward using confidence intervals to compare correlations. Psychological Methods, 12, 399-413. DOI:10.1037/1082-989X.12.4.399 
Tables

Table 1. Scale descriptive information and inter-scale correlations

\begin{tabular}{lcccccccccc}
\hline & $\alpha$ & Mean & $S D$ & Min & Max & 1 & 2 & 3 & 4 & 5 \\
\hline 1. GCB & .89 & 43.56 & 10.94 & 15.00 & 70.00 & & $.64^{* *}$ & $.45^{* *}$ & $.44^{* *}$ & $.36^{* *}$ \\
2. GMC & .86 & 18.75 & 6.25 & 5.00 & 35.00 & & $.48^{* * *}$ & $.47^{* *}$ & $.38^{* *}$ \\
3. RPBS & .94 & 74.17 & 30.22 & 26.00 & 148.00 & & & $.89^{* *}$ & $.85^{* *}$ \\
4. NAP & .91 & 19.86 & 6.68 & 6.85 & 34.22 & & & & $.78^{* *}$ \\
5. TPB & .81 & 21.11 & 5.75 & 11.16 & 35.40 & & & & \\
\hline
\end{tabular}

GCB, Generic Conspiracist Beliefs; GMC, General Measure of Conspiracism; RPBS, Revised Paranormal Belief Scale; NAP, New Age Philosophy; TPB, Traditional Paranormal Belief

Table 2. Problem task descriptive information and inter-item correlations

\begin{tabular}{lcccccccc}
\hline Variable & $M$ & $S D$ & Proportion & $S D$ & 1 & 2 & 3 & 4 \\
\hline 1. Perception of Randomness & 3.71 & 1.03 & 74.23 & 20.54 & $.29 * *$ & $.16^{* *}$ & .03 & $.14 *$ \\
2. Standard Conjunction & 1.75 & 1.22 & 35.04 & 24.37 & & $.32 * *$ & $.21^{* *}$ & $.31 * *$ \\
3. Everyday Conjunction & 3.67 & 1.20 & 73.33 & 24.00 & & & $.47 * *$ & $.27 * *$ \\
4. Conspiracy Conjunction & 4.20 & 1.04 & 83.90 & 20.86 & & & & $.26 * *$ \\
5. Paranormal Conjunction & 4.34 & 1.00 & 86.83 & 20.09 & & & & \\
\hline
\end{tabular}

Table 3. Correlations between problem solving task performance, conspiracy measures and belief in the paranormal

\begin{tabular}{llllll}
\hline Variable & GCB & GMC & RPBS & NAP & TPB \\
\hline Perception of Randomness & -.07 & -.08 & $-.25^{* *}$ & $-.21 * *$ & $-.22^{* *}$ \\
Standard Conjunction & $-.22^{* *}$ & $-.15^{* *}$ & $-.16^{* *}$ & $-.16^{* *}$ & $-.19^{* *}$ \\
Everyday Conjunction & $-.16^{* *}$ & $-.16^{* *}$ & $-.20^{* *}$ & $-.16^{* *}$ & $-.24 * *$ \\
Conspiracy Conjunction & $-.22^{* *}$ & $-.18^{* *}$ & $-.13^{*}$ & $-.14^{* *}$ & $-.12^{* *}$ \\
Paranormal Conjunction & $-.25^{* *}$ & $-.26^{* *}$ & $-.42^{* *}$ & $-.36^{* *}$ & $-.32 * *$ \\
\hline
\end{tabular}

GCB, Generic Conspiracist Beliefs; GMC, General Measure of Conspiracism; RPBS, Revised Paranormal Belief Scale; NAP, New Age Philosophy; TPB, Traditional Paranormal Belief 


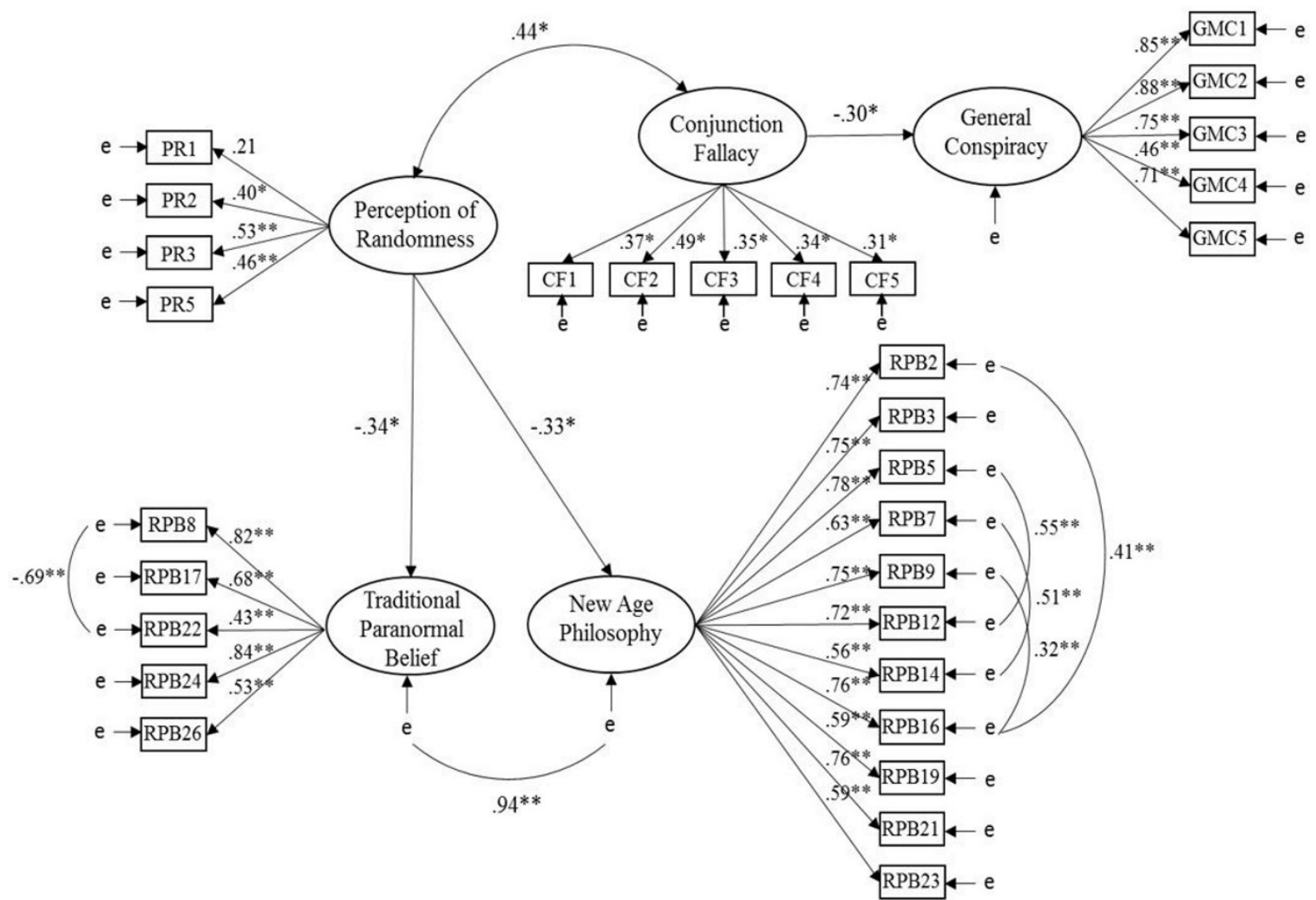

Fig 1 Model 1: Relationships of Perception of Randomness with Paranormal Belief factors, and Conjunction Fallacy with General Conspiracy. Note. Latent variables are represented by ellipses; observed variables are represented by rectangles; error of measurement is indicated by 'e'; * indicates $p<.05, * *$ indicates $p<.001$ 


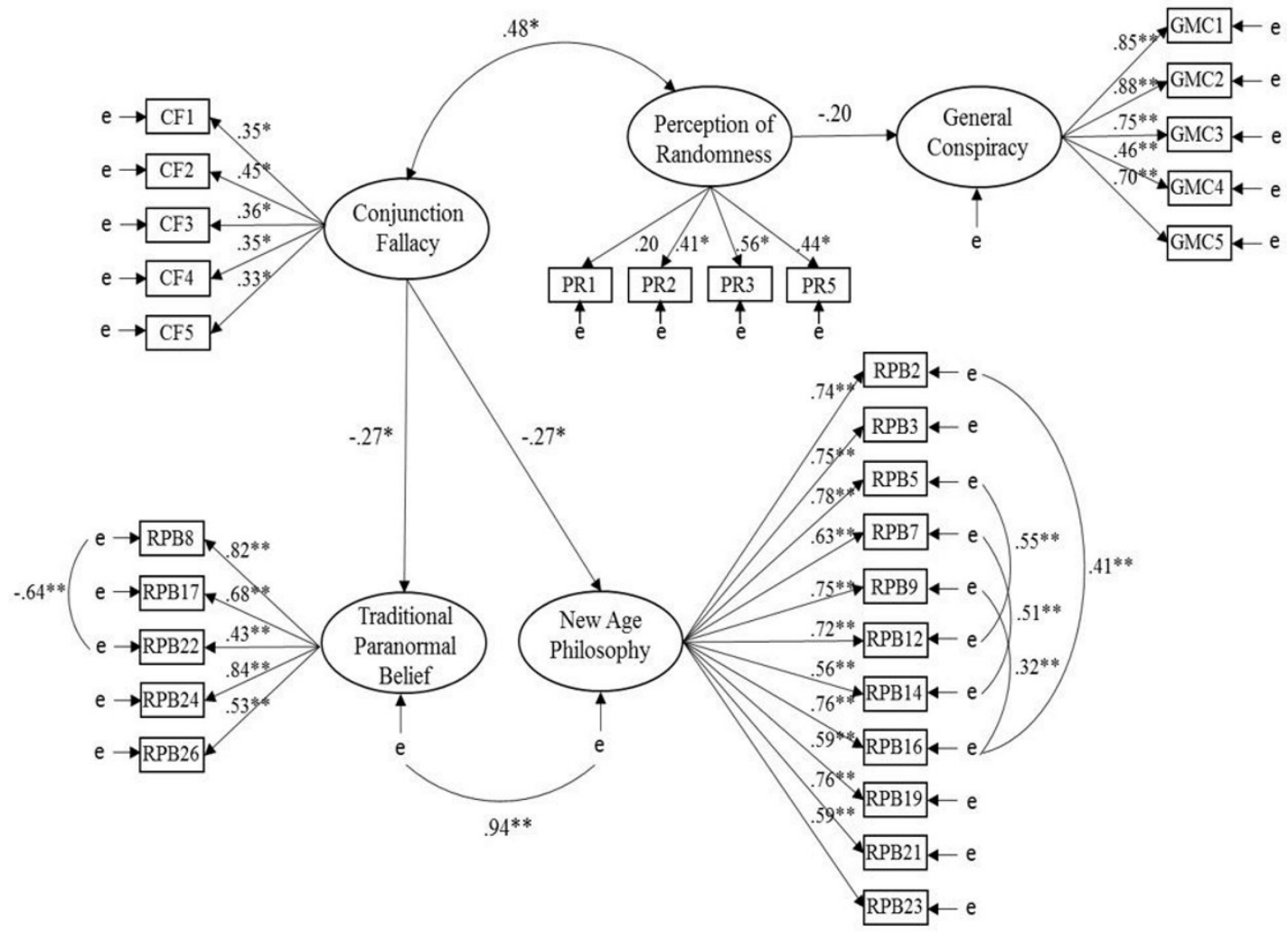

Fig 2 Model 3: Relationships of Conjunction Fallacy with Paranormal Belief factors, and Perception of Randomness with General Conspiracy. Note. Latent variables are represented by ellipses; observed variables are represented by rectangles; error of measurement is indicated by 'e'; * indicates $p<.05, * *$ indicates $p<.001$. 